\title{
MEMORIAS INSTANTÁNEAS A PRUEBA DE ARCHIVO ${ }^{1}$
}

\section{ARCHIVE-PROOF INSTANTANEOUS MEMORIES}

\author{
LUCíA ÁlvAREZ \\ luciaalvarezpintado@gmail.com \\ Instituto de Historia del Arte Argentino y Americano. Facultad de Bellas Artes \\ Universidad Nacional de La Plata. Argentina
}

Recibido 9/3/2018 | Aceptado 16/7/2018

\section{Resumen}

En este trabajo deseamos recuperar y excavar en las representaciones de archivo que se desprenden de las voces que frecuentan e invocan modos de nombrar y de resistir las prácticas de documentación de los cuerpos movilizados en acciones poéticas y políticas subterráneas durante la posdictadura. La primera parte revisa y releva la teoría anglófona que reconoce a los estudios sobre performance como campo de acción, mientras que el segundo segmento de este trabajo recupera las voces que protagonistas y testigos oculares del under vuelcan sobre la condición de la práctica indocumentada, las memorias descartadas y otros artefactos lingüísticos a prueba de archivo.

\section{Palabras clave}

Efímero; documentación de la práctica artística; cuerpos; archivos

\section{Abstract}

In this work we want to recover and dig in the representations of archive that come out of the voices that frequent and invoke ways to name and resist the documentation practices of mobilized bodies in underground poetic and politic actions during the post-dictatorship. The first part reviews the Anglophone theory that recognizes performance studies as a field of action, while the second part recovers the voices of protagonists and eyewitnesses of the under related to the condition of undocumented practices, discarded memories and other archive-proof linguistic artifacts.

\section{Keywords}

Ephemeral; documentation on the artistic practice; bodies; archives

\footnotetext{
${ }^{1}$ La escritura de este artículo se inscribe a un proyecto de beca radicado en el Instituto de Historia del Arte Argentino y Americano de la Facultad de Bellas Artes, denominado Archivos inestables y prácticas artístico políticas en los ochenta. El caso del Archivo Batato Barea, dirigido por la Mg. María de los Ángeles De Rueda.
} 
«Tengo ahora la impresión de que el mejor paradigma de la huella [...] no es, como algunos lo creyeron y él también quizás, la pista de caza, el abrirse paso, el surco en la arena, la estela en el mar, el amor del paso por su impronta, sino la ceniza (lo que resta sin restar del holocausto, del quema-todo, del incendio el incienso).» Jacques Derrida [1987] (2009)

Con frecuencia, la documentación de la práctica artística suministra materiales que, al archivarse, se colocan a disposición de la investigación histórica y de la producción de exposiciones. No obstante, la historia de la documentación de las artes del cuerpo durante la posdictadura diagrama otras lógicas, que apremian interrogar los modos por los cuales la memoria efímera del cuerpo exhibe su deliberada resistencia al archivo o bien se graba en un soporte precario y sobreviene allí un recuerdo borroso y por momentos ilegible.

Los Peinados Joli, Las Gambas al Ajillo, Batato Barea, Las inalámbricas, Fernando Noy, Liliana Maresca, entre otros, se integran en una genealogía de prácticas - absorbidas luego bajo el anglicismo underque durante los ochenta diseñaron «formas moleculares de resistencia» (Lucena, 2014, p. 119) y colmaron los espacios subterráneos instando a la recuperación y a la reinvención de los lazos de sociabilidad y de afectividad quebrados por el aparato represivo militar. El recuerdo de estas acciones repone el deseo de poner el cuerpo en acción, el destape de un goce fugaz, momentos intermitentes en los que la alegría logró desbordar las existencias paralizadas por el terror.

Escasamente registrados, perdidos o rememorados con marcas de olvidos y con tachaduras, la posibilidad de recuperar la densidad crítica de estas poéticas colisiona con la sanción de su no retorno, la negativa a documentar prácticas que, por su ontología efímera, se sujetan a una condición irrepetible y se exponen, por tanto, a una desaparición programada como destino inminente. Sobre la documentación que aspira a conservar retazos de estas acciones escurridizas se vuelca una sospecha: ¿se archiva la memoria de los cuerpos? La impronta del archivo es la de aquel que profana lo irrepetible y lo devuelve aplanado, reificado, despojado de su potencia crítico-poética.

Contra la contundencia de aquel diagnóstico, ciertas zonas de estas acciones corporalizadas lograron, no sin dificultades, sortear su lábil permanencia para grabarse en un soporte que, aunque borroso, es visualizable por segmentos; es casero y precario, y pulsa por restituir partes de una memoria que no aspira a ser completa y sistemática. 
Los responsables del registro de esa memoria efímera - partícipes activos o testigos oculares de la «movida» under-reunieron las esquirlas de aquellos años intempestivos y coleccionaron memorias materiales, cuya condición dispersa y errática las encuentra diseminadas en cajas, anaqueles y bibliotecas personales o bien desechadas pasado cierto tiempo. Actualmente, estos fondos sobreviven como souvenirs cuya circulación incierta demanda a la historiografía revisar las formas de narrar lo que apenas deja huella, ponderando lo horadado, las lagunas y las fallas de la memoria como dimensiones productivas capaces de reponer la textura de aquellas prácticas.

En guaridas remotas tuvieron y tienen lugar experiencias de archivos caseros, colecciones que profanan un concepto archivado de la palabra archivo (Derrida, 1997) y que combaten la resignación de esta memoria a la vez que instalan la incertidumbre en torno a qué es lo recuperable de estas prácticas (Carvajal, 2010). En muchos casos, se trata de acervos pendientes de catalogación, memorias a desclasificar, restos que aguardan ser desempolvados, sostenidos desde una red de afectos que apuestan a la promesa que estos contienen para el porvenir. Los imaginarios volcados sobre la documentación de estas poéticas corporalizadas devuelven imágenes de distinto tenor que amplifican una noción de lo irrecuperable, lo no registrado por descuido o por convicción y, finalmente, aquello que, aún registrado, fue extraviado o descartado.

Por su parte, la teoría consagrada a este campo de estudios transita, desde sus inicios, entre productivos desacuerdos que remiten a la dimensión archivable de un cuerpo, la ontología del presente y los tráficos de economías sensibles. En este trabajo deseamos interrogar sobre los modos en que estas voces configuran y distribuyen un cierto tipo de representación del archivo de las artes del cuerpo. Los efectos de estas regularidades discursivas proliferan en formas de nombrar y de imaginar una noción archivada (clausurada) o por desarchivar de la palabra archivo.

En la genealogía de escrituras sobre performance y archivo, la aparición de Unmarked, the politics of performance (1997a), de Peggy Phelan, y más precisamente, la notoriedad adquirida por un extracto de aquella obra, registran un campo de estudios emergente -los performance studies - plagado de indeterminaciones semánticas:

La única vida de la performance está en el presente. La performance no puede ser guardada, grabada, documentada, o de otra forma, participar en la circulación de representaciones: una vez que lo hace, se vuelve otra cosa distinta de performance [...] El ser de la performance, como la 
ontología de la subjetividad aquí propuesta, se vuelve sí misma a través

de la desaparición (p. 146). ${ }^{2}$

La escritura incendiaria de Peggy Phelan resuena en la batalla por la sanción de sentidos estrictos, claros y distintos, y desencadena una serie de recepciones críticas que, con distinta intensidad y fuerza argumentativa, aspiran a contrarrestar el presunto retorno de una metafísica del presente. Encorsetada como una ontología devota del instante evanescente e irrecuperable, la criticidad pendiente en el texto se disipó en el rastrillaje obsesivo de este fragmento, cuyos ecos son también sintomáticos de una cultura ofuscada en el ejercicio de un registro frenético, inventarios prolijos, archivos disciplinados y otras prótesis de la memoria.

El acento contenido en la experiencia sensible que no deja trazos ni despojos y que se disipa sin otro asidero más que la memoria testimonial y escrita, desmoviliza a una teoría de los medios obstinada en indicar la condición de igualdad que rige entre lo vivo y lo revivido por intermediación de artefactos que suplementan y sostienen aquel instante fugaz. La publicación del libro de Philip Auslander, Liveness: Performance in a Mediatized Culture (1999) se inscribe como parte de los intentos por desacreditar la prístina ontología del presente endilgada a Phelan. La puesta en texto de la frase célebre e históricamente desdichada que reproducimos hace unas líneas se compagina con la fervorosa respuesta de Auslander:

Lejos de ser invadida, contaminada, o amenazada por la mediación, la performance en vivo se encuentra siempre inscrita con los rastros de la posibilidad de la mediación técnica [...] eso la define como viva [...]. De manera similar, sobre la performance en vivo no puede afirmarse que esta tenga prioridad ontológica o histórica sobre la mediatización, desde que lo vivo se hace visible por la posibilidad de la reproducción técnica. Lo vivo no puede existir sino sólo dentro de una economía de la reproducción (p. 53). ${ }^{3}$

\footnotetext{
${ }^{2}$ «Performance's only life is in the present. Performance cannot be saved, recorded, documented, or otherwise participate in the circulation of representations of representations: once it does so, it becomes something other than performance [...] Performance's being, like the ontology of subjectivity proposed here, becomes itself through disappearance» (p. 146). Traducción de la autora del artículo.

${ }_{3}$ «Far from being encroached upon, contaminated, or threatened by mediation, live performance is always already inscribed with traces of the possibility of technical mediation [...] that defines it as live [...] Similarly, live performance cannot be said to have ontological or historical priority over mediatization, since liveness was made visible only by the possibility of technical reproduction [...] The live can exist only within an economy of reproduction» (Auslander, 1999, p. 53). Traducción de la autora del artículo.
} 
Sobreviene en la escritura de Auslander una retórica que insiste en descalzar el binarismo contenido en la escisión entre el en vivo y los medios capaces de apresar la entidad provisoria del aquí y ahora. Una ortopedia de la memoria esquiva parece suplementar lo ingrávido de estos eventos predestinados a la pérdida (Phelan) o arados por una técnica productora de indicios y certezas de lo que fue (Auslander). Registro, por lo tanto existió parece designar la proposición lógica que estructura una teoría, que se despedaza ante la evidencia de las fisuras que entre el acontecimiento y el documento marcan la posibilidad de una reconstrucción dañada, las fallas de la indexicalidad y lo que es aún más potente y consecuente: la producción de lo desigual como motor de toda economía de la representación y la reproducción. En este sentido, arrogarse la potestad de restituir existencias volátiles y cuerpos fantasmáticos por la simple voluntad de registro equivale a desconocer o bien a ignorar la intrincada red de tráficos de economías sensibles, cuya puesta en imagen se debate entre la inteligibilidad pendiente y la expropiación adulterada de la diferencia.

Añadimos a las voces que auditan y que revisan la condición impermanente del cuerpo en acto, «In the meantime. Performance Remains», tercer capítulo del libro de Rebecca Schneider, Performing remains. Art and war in times of theatrical reenactment (2001). Movilizada por la condición vaporosa y efímera que regula y que ajusta buena parte de los incipientes estudios sobre performance, ${ }^{4}$ Schneider confecciona en ese capítulo una genealogía de recurrencias y de desplazamientos teóricos que titula A small history of ephemerality [Una breve historia de lo efímero]. Allí recopila la emergencia de ciertas nociones, que transitan desde menciones fortuitas hasta constituirse en vocabulario de uso frecuente.

Hacia 1965, Richard Schechner propone ejercitar una noción de teatro que se remonta al enredo entre la permanencia y lo efímero, mientras que en 1974 establece que «es un evento caracterizado por lo efímero y la inmediatez ${ }^{5}$ (Schechner en Schneider, 2001, p. 94). Entre las décadas del setentay del ochenta el desvanecimiento (vanishing) se impone como marca lingüística, que resuena intensamente en el sistema categorial volcado sobre la palabra performance. Schneider recupera la copiosa circulación y divulgación de ideas procedentes del postestructuralismo francés y presume que, posiblemente, la gravitación de ideas fuerza

\footnotetext{
Schneider contextualiza estas disquisiciones en el marco de la creación del Departamento de Estudios sobre Performance [Department of Performance Studies] en la Universidad de Northwestern, Estados Unidos, hacia el año 1985.

5 Schneider contextualiza estas disquisiciones en el marco de la creación del Departamento de Estudios sobre Performance [Department of Performance Studies] en la Universidad de Northwestern, Estados Unidos, hacia el año 1985.
} 
como el sous rature derridiano ${ }^{6}$ derivaron en una traducción literal de la tachadura devenida en desvanecimiento de la acción corporalizada. Para el año 1985, indica la autora, el desvanecimiento y la desaparición como ontología del evento irrepetible adquiere la condición de un mantra aplicado sin discreción y enarbolado por el propio Schechner (en Schneider, 2001):

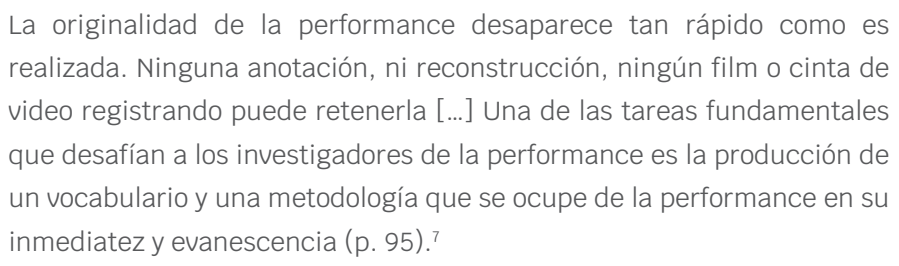

Es una acción que se escurre ante la mirada atónita de unos medios expectantes del santiamén en que lo fugaz y lo volátil se congelen en una imagen, donde sobrevenga al menos una huella o esquirla de lo que fue y jamás volverá. El deseo de demorar y de almacenar un instante de experiencia sensible adquiere la forma de una empresa fallida, pues ninguna anotación, ni reconstrucción puede retenerla (Schechner en Schneider, 2001). Lo que en palabras de Schechner no llega a ser inscripción, reaparece y se exaspera, al decir de Schneider, en la denostada proposición de Phelan (1997), por la cual, la performance no puede ser guardada, grabada, documentada (Phelan, 1997a). En el contexto de Unmarked (1997a), de Phelan, lo efímero e inmediato se expanden hacia una «asociación de la performance con la pérdida, la desaparición y la muerte» (Schneider, 2001, p. 95).

Interpelada fuertemente por la condición agónica que recubre a la performance - según lo sostienen Schechner y Phelan-, Schneider se interroga por la posibilidad de exhumar una reflexión que revise el modo en que la impermanencia y la pérdida de la acción corporalizada sostiene -antes que rechaza- intensos vínculos con las lógicas (imperialistas y patriarcales) que regulan el funcionamiento del archivo. En tal sentido, la consignación de la performance como (in)

\footnotetext{
${ }^{6}$ La noción de sous rature puede traducirse como una escritura bajo tachadura, y en términos derridianos hace referencia al uso de una palabra cuyo significado resulta indeterminado pero a la vez necesario en el contexto de las restricciones que impone el lenguaje, por lo que la supresión contenida en la tachadura no disuelve sino que conserva la materialidad de la palabra con los indicios de su situación en la textualidad. 7 «Performance originals disappear as fast as they are made. No notation, no reconstruction, no film or videotape recording can keep them [...] One of the chief jobs challenging performance scholars is the making of a vocabulary and methodology that deal with performance in its immediacy and evanescence» (Schechner en Schneider, 2001, p. 95). Traducción de la autora del artículo.
} 
archivable tendería a reforzar antes que a desgastar la lógica patriarcal que gobierna al archivo desde que este se instituye $-y$ aquí resuena Derrida (1997) - en la ley de un nombre y de un hombre. Remarca, por otra parte, que en el archivo lo cadavérico (the bones) habla en memoria y en lugar de la carne, materia escandalosa cuyos excesos se derraman como un excedente (un fuera-de-archivo) que urge disimular y desaparecer (Schneider, 2011). Por otra parte, insiste en recuperar la idea postestructuralista por la cual la desaparición le imprime su marca indeleble al documento, al registro y a toda forma de permanencia (remain) que resista desde la trinchera de un cuerpo material, pues la permanencia contiene a la pérdida como dimensión que estructura su empeño en existir.

Por su parte, José Esteban Muñoz (2008) recupera, junto con Schneider, una dimensión diferencial de lo efímero, no como lo que se desvanece sin rastro, sino más bien como «una especie de evidencia de lo que ha transpirado pero no ciertamente lo cosa en $\operatorname{sí»}^{8}$ (p. 9). Una imagen próxima a un santo sudario de la performance prolifera en aquella descripción, a la que se añaden las «huellas, destellos, residuos y manchas de cosas» ${ }^{9}$ (Muñoz, 2009, p. 10) cuya inteligibilidad reconstruye los rastros del evento efímero revocando la condición de su pérdida inminente.

Escrituras recientes, como el ensayo de Marco Pustianaz «Un/Archive» (2013), incluido dentro de la compilación Performing Archives/ Archives of Performance, proponen desmarcar las ya exhaustas y desgastadas palabras de Peggy Phelan, confinadas por sus detractores a la expresión de una negatividad plena e improductiva. Releída como parte un proyecto queer-feminista en alianza con las proposiciones de Lee Edelman en No Future: Queer Theory and the Death Drive (2004), Pustianaz (2013) replica el afamado fragmento (evocado hasta la condición de un rezo) y sostiene:

Si repito una vez más la cita, es porque me gustaría insistir en su negatividad como una negatividad queer. Aunque el impulso de archivo claramente continuará guardando, documentando y registrando performance(s), performance es tomada aquí para ser el resto innombrable que 'es' o continúa siendo, lo que no puede ser guardado, documentado o registrado. Tal ontología del ser, se mantiene como un recordatorio del excedente que, como en lo queerness de Edelman escapa a la significación (p. 475). ${ }^{10}$

8 "[...] a kind of evidence of what has transpired but certainly not the thing itself» (Muñoz, 2009, p. 9). Traducción de la autora del artículo.

"[...] traces, glimmers, residues and specks of things» (Muñoz, 2009, p. 10).

Traducción de la autora del artículo. 
El autor reanuda una lectura demorada de Unmarked y presiona sobre las dimensiones críticas inadvertidas o desechadas de cara a la divulgación de versiones retaceadas de la obra. La objeción que la acción corporalizada traduce en su condición fuera-de-archivo tiene asidero, entonces, en el ejercicio de una resistencia que rechaza la reactualización poética en el contexto de tráficos de economías sensibles y de mercados de lo inteligible que negocian con el valor de la diferencia en la sustracción de sus singularidades: «mujeres y performers, frecuentemente son "guionadas» para «vender» o «Confesar» algo a alguien que está en la posición de comprar o perdonar» (Phelan, 1997a, p. 163). ${ }^{11}$

Una ontología de la pérdida —según Phelan - resuelta a atascar las maquinarias que aceitan la reproducción de representaciones de representaciones y que aseguran la circulación del capital económico y sensible empatiza, ciertamente, con la negatividad expresada por Edelman hacia una plataforma de futuridad sostenida en la reproducción (heteronormada) de las existencias. Lo que se desmarca de la historia, lo que desborda del archivo y produce un excedente errático, lo que no llega a decodificarse pues excede las estructuras de significación, reúne los pulsos de ambos proyectos y corroe, por otra parte, una representación del archivo como «narrativa de la abundancia, la oportunidad y la visibilidad universal, viajando hacia un futuro»»12(Pustianaz, 2013, p. 466), a la vez que instala la incertidumbre en torno a la posibilidad de tallar una contra-memoria en la cara del archivo hegemónico. Phelan (1997b) replica años más tarde de su afamada frase:

Mi presentimiento es que el esbozo afectivo de lo que hemos perdido nos acerca a los cuerpos que todavía queremos tocar aún más que

la ilustración restaurada. 0 al menos el hueco de ese esbozo podría

10 "If repeat once more the quotation, it is because I would like to insist on her negative as a queer negative. Although the archival impulse clearly will continue to save, document and record performance(s), performance is here taken to be the unnameable remainder that "is", or continues to be, what will not be saved, documented, recorded. Such ontology of being, is upheld as a reminder of the surplus wich, like Edelman's queerness scapes signification» (Pustianaz, 2013, p. 475). Traducción de la autora del artículo.

${ }^{11}$ "Womens and performers, more often than not, are "scripted" to "sell" or "confess" something to someone who is in the position to buy or forgive» (traducción de la autora del artículo).

12 "Womens and performers, more often than not, are "scripted" to "sell" or "confess" something to someone who is in the position to buy or forgive» (traducción de la autora del artículo) 
permitirnos entender más profundamente por qué seguimos sosteniendo

cuerpos que se han ido (p. 3)..$^{13}$

Preguntarle a los huecos, a lo recóndito de una memoria que se tensa entre el deseo nostálgico de retener las huellas y el desprendimiento del lugar de una imagen deshabitada, ausente de cuerpos y hálito vital, puede contener un proyecto crítico que descalce la asimilación desconflictuada del cuerpo archivado. No obstante, recrear el poder de estas dimensiones en el contexto de archivos latinoamericanos movilizados por la recolección, por los retazos de las memorias corporales de la disidencia sexual y poética, nos exhorta a agudizar el ejercicio de una vigilancia epistemológica, que exhume las singularidades y que reconozca la materialidad de estos fondos como no siempre ni necesariamente «mensurable, entera, palpable, correcta, juzgable en términos de "verdad" o "falsedad"» (Davis y otros, 2014).

\section{La tendencia del instante indocumentado}

Restituir las palabras de archivo que se derraman sobre los fondos constituidos durante la postdictadura sobre la base de pasiones recolectoras y recuperar las resistencias, detracciones y disposiciones por las cuales no hubo archivo, puede constituirse en la estrategia que excave en las representaciones que pulsan en los discursos y producen modos de imaginar vidas en el archivo o fuera de él.

De entre estas voces, quizá la más estridente, por su alocutario y sus efectos, proviene del testimonio de Antonio Gasalla (en Noy, 2001): «En otros países como en Francia, el under se graba, todo queda prolijamente guardado en el Museo de Arte Moderno. Acá nada de eso» (p. 73). Entre categórico y nostálgico, Gasalla cimenta una versión en la que el registro dañado, disperso y precario equivale a la ausencia de archivos del under. El lamento por una memoria televisada que no fue -Batato muere dejando pendiente su participación en el programa de Gasalla - y un archivo que se añora adherido al barrido de la imagen, igualado a una emisión sin interferencias, ni ruido, inquieta en la medida en que la prolijidad que se predica de aquel distribuye y modela a los cuerpos a la medida de depósitos y anaqueles que extirpan los excesos, los desbordes y los remanentes de las memorias corporalizadas.

${ }^{13}$ «My hunch is that the affective outline of what we've lost might bring us closer to the bodies we want still to touch than the restored illustration can. Or at least the hollow of the outline might allow us to understand more deeply why we long to hold bodies that are gone» (Phelan, 1997, p. 3). Traducción de la autora del artículo. 
Otras declamaciones parecen afiliarse y remontarse a la exhortación de un cuerpo en acción que no se archiva más que en el terreno de una memoria afectiva expuesta, no obstante, a las trampas que traman los olvidos y las tachaduras en su dimensión productiva. Marcia Schwartz (en Suárez, 2016) invoca en una entrevista: «Había una reivindicación del instante y no era la tendencia documentar» (p. 167); proposición que reaparece en la voz de Katja Alemann (en Lucena \& Laboureau, 2016):

\footnotetext{
Algunos registros hacíamos porque teníamos ganas. Yo había traído una cámara de Alemania que era una de esas primeras Beta que salían, medio chiquita. Jugaba con esa cámara y hacíamos cosas más bien experimentales, nunca documentábamos (p. 70).
}

El archivo que el viento se llevó, parafraseando parte de aquel testimonio, es en principio un alivio que mitiga la imagen de un pasado que retorna problemáticamente íntegro, pero, a la vez, sobre esos papeles en el viento se sobreimprime un afecto melancólico que por a momentos se disipa mientras que al otro instante presiona por devolver fragmentos de un pasado que aún relampaguea.

En un registro similar al de Schvartz, Seedy González Paz, actual albacea del Archivo Batato Barea, recuerda: «Eran shows. Y la premisa era no documentar, no filmar, no grabar lo que se hacía» (González Paz en Dubatti, 1995, p. 113). Las imágenes que surcan estas existencias indocumentadas, (an)archivadas y exoneradas de la disciplina del documento y que, por otra parte, conservan el recuerdo de una experiencia sofocante de registro y vigilancia, se distienden también hacia la resonancia de lo que no perdura por fragmentario o bien por alimentar una economía del recuerdo que colisiona con el imaginario de un goce sin réplicas: «Ahora no se goza. Se registra. Y el goce necesita de la desaparición. Si estás pensando en registrarlo, estás pensando en gozarlo más adelante» (Molina en Moreno, 2003, s/p). Con respecto a Escenas de los ochenta (2003), exposición realizada en Fundación Proa, Daniel Molina dice que registrar es posponer el goce y aquel se desvanece al instante sin dejar marcas. De este modo, deja pendiente la pregunta sobre qué narrativas del goce aguardan demoradas en la sanción de su condición irretornable.

Daniel Melero (en Lucena \& Laboureau, 2016) agrega a estas disquisiciones: «Hubo un show de Los Encargados donde subió Omar [Chabán] al escenario. [...] Lo recuerdo y lo tuve guardado en un cassette, pero ya no lo tengo más y tal vez terminó en una caja que fue a la basura. Está bien, es su destino» (p. 85). A su vez, Silvia Armoza (en Noy, 2001) añade con relación a Batato Barea: «Una noche se 
me apareció cargado de golosinas. Iba a hacerse un traje con ellas. Por ahí, desparramados en distintas mudanzas, todavía quedan trozos del vestido-banquete aquel» (p. 78).

La invención de estas memorias como descartables reenvía al basurero de la historia (Marcus, 2012) el cementerio de las memorias (in) consignadas, las esquirlas de recuerdos (souvenirs) que, inadaptados a la economía de la repisa o el estante doméstico, sufren el destierro y el entierro que los desecha, al mismo tiempo que estos basurales (historiográficos y literales) contienen la promesa de la exhumación anunciada por Greil Marcus (2013): «Nada está muerto para siempre; todo sentido tendrá su fiesta de retorno» (p. 22).

\section{Donde hubo instante, ¿archivos quedan?}

Frecuentemente sospechado de normalizar y de encarrilar las existencias poéticas sinuosas que desbordan de la norma de su espacio instituyente, el archivo sostiene alianzas inestables e indeterminadas con los remanentes de los cuerpos y las memorias que aspira a retener. Por su parte, aquella materia vital le impone y le exige con toda intensidad imaginar otros modos de habitar y afectar el recuerdo desde coordenadas que no usufructúen con el trazado de una diferencia traducida, atemperada a la medida de la creciente demanda de politicidad digerida para el mercado de consumo de lo sensible.

En Los ochenta recienvivos. Poesía y performance en el Río de la Plata (2013), Irina Garbatzky entiende que la documentación escasa y esporádica de la acción corporalizada corresponde a una voluntad de hacer que rechaza la sistematización y el registro, con la salvedad de Batato Barea, quien meticulosamente consigna y archiva cada una de sus actividades. La autora sostiene que esta actitud reticente al registro se cierne frente a lo que se imagina y valora como ausencia de futuridad a la vez que recupera una noción de performance como «acontecimiento sin monumento» (Garbatzky, 2013, p. 24), frase que colisiona con la voluptuosa y firme evidencia del busto de Batato Barea que se descubre en ocasión de un homenaje realizado en 1992, y que evoca Seedy González Paz (en Dubatti, 1995):

A nosotros, de todas maneras, eso del busto nos choca un poco. Parece como entrar en el establishment: una persona pasa a ser un busto y un museo. Ayer hablábamos con Alejandro Urdapilleta y me decía: «A mí no me gusta que usen la palabra museo». Pero en el fondo está bien, porque Batato trabajaba con poesía y no hay nada más antiguo, esquemático y académico que la poesía (p. 155). 
Daniel Lucena y Gisela Laboureau (2016) recuerdan los contactos con estas guaridas de memoria under: "Cada uno de los artistas había aportado algo: un recuerdo, un registro, una reminiscencia de aquella época, que escondidos en un cajón esperaban su tiempo para ser mostrados desafiando el deterioro de los años» (p. 32).

Eneltrazadodealgunasintuicionesqueaparecencomodesprendimientos de este trabajo, entendemos que es preciso, sino urgente, interrogar sobre las fricciones que se jalonan entre la resistencia al archivo y la confección de fondos insospechados, cajoneados, donde se demoran jirones de eventos sin expectativas de retorno, fotos, volantes y grabaciones erráticas, retazos archivados, empolvados de olvido. Si del archivo se sospecha, también demandamos sospechar de su ausencia irrevocable, y preguntar ¿ahí hubo/ hay archivo?, inquietud que se instala en el contexto de pasiones recolectoras, memorias acopiantes de recuerdos tachados, descalibrados y fallidos en la temporalidad de un archivo de accesos y salidas administrativas, intolerante de los tiempos demorados y ociosos que diagraman esos (otros) archivos afectados, afectantes y afectivos.

Hurgar en los basurales de la memoria, diseñar modos de dar a ver la falla y los huecos de las trazas de un cuerpo que desconcierten y que traicionen las demandas de inteligibilidad diáfana, proponer coordenadas que hagan pensables y practicables los momentos en que la imagen de archivo retrocede y la obturación resulta hostil. Vociferar una negatividad que traba el ejercicio de historiografías de la cicatrización (Love en Cuello, 2016) y exhorta a la desmesura de la herida abierta, pueden revestir claves de ingreso a proyectos que desarchiven representaciones de archivos prolijos, desbaratados, cancelados por el monopolio de un goce sin lugar para la marca, desperdigados en rincones recónditos, devueltos en la pulsión de un recuerdo que abre cajones y narra sobre las esquirlas.

\section{Referencias}

Auslander, P. (1999). Liveness: Performance in a Mediatized Culture. Londres, Inglaterra y Nueva York, Estados Unidos: Routledge.

Carvajal, F. (2010). Encarnar el archivo. Notas sobre archivos y artes del cuerpo. En M. García Moggia (Cord.), Archivo. Prospectos de arte (pp. 4359). Valparaíso, Chile: Centro de Documentación de las Artes Índice.

Cuello, N. (2016). Metodologías de la decepción: Estrategias críticas para la investigación en prácticas artísticas contemporáneas y políticas sexuales. En A. C. Arias y M. D. López. (Eds.), Indisciplinas. Reflexiones sobre prácticas metodológicas en ciencias sociales (pp. 59-178). La Plata, Argentina: Club Hem editores. 
Davis, F. y otros (18 de noviembre de 2014). Poéticas de la falla, archivos dañados y contraescrituras sexopolíticas de la historia del arte. Ponencia presentada en el Coloquio Internacional de una raza sospechosa: arte/ archivo/memorias/sexualidades. Biblioteca de Santiago de Chile, Chile.

Derrida, J. (1997). Mal de archivo. Una impresión freudiana. Madrid, España: Editorial Trotta.

Derrida J. [1987] (2009). La difunta ceniza. Buenos Aires, Argentina: Ediciones La Cebra.

Dubatti, J. (1995). Batato y el nuevo teatro argentino. Buenos Aires, Argentina: Atlántida.

Edelman, L. (2004). No Future: Queer Theory and the Death Drive. Durham, Estados Unidos: Duke University Press.

Garbatzky, I. (2013). Los ochenta recién vivos. Poesía y performance en el Río de La Plata. Rosario, Argentina: Beatriz Viterbo Editora.

Marcus, G. (2012). El basurero de la historia. Buenos Aires, Argentina: Paidós. Moreno, M. (28 de diciembre de 2003). La generación del ochenta. Página 12. Recuperado de https://www.pagina12.com.ar/diario/suplementos/ radar/9-1149-2003-12-28.html

Muñoz, J. E. (2008). Ephemera as evidence: Introductory Notes to Queer Acts. Women \& Performance: a journal of feminist theory, 8(2), 5-16. doi: 10.1080/07407709608571228

Noy, F. (2001). Te lo juro por Batato. Buenos Aires, Argentina: Libros del Rojas.

Lucena, D. (2014). Estrategia de la alegría. En Perder la forma humana. Una imagen sísmica de los años ochenta en América Latina (pp. 117-121). Madrid, España: Museo Nacional Centro de Arte Reina Sofía.

Lucena D. y Laboureau, G. (Comps.). (2016). Modo mata moda. Arte, cuerpo y (micro)política en los 80. Recuperado de http://hdl.handle.net/10915/63246 Phelan, P. [1993] (1997a). Unmarked: The Politics of Performance. Londres, Inglaterra: Routledge.

Phelan, P. (1997b). Mourning Sex: Performing Public Memories. Londres, Inglaterra y Nueva York, Estados Unidos: Routledge.

Pustianaz, M. (2013). Un/Archive. En G. Borggreen y R. Gade (Eds.), Performing Archives/ Archives of Performance (pp. 465-480). Copenhagen, Dinamarca: Museum Tusculanum Press.

Schneider, R. (2011). In the meantime: performance remains. En Performing remains. Art and War in Times of Theatrical Reenactment (pp. 87-110). Londres, Inglaterra y Nueva York, Estados Unidos: Routledge.

Suárez, M. (2016). La noche de los ochenta era divina. En D. Lucena y G. Laboureau (Comps.), Modo mata moda. Arte, cuerpo y (micro)política en los 80 (pp. 163-173). Recuperado de http://hdl.handle.net/10915/63246 